\title{
Carbamoylation using the Co-containing Copper Complex derived from Lithium $N$-Methylanilide
}

\author{
Yoshiaki Wakita, Toshio Kobayashi, Minoru Maeda and Masaharu Kojima* \\ Faculty of Pharmaceutical Sciences, Kyushu University, Maidashi \\ 3-1-1, Higashi-ku, Fukuoka 812, Japan
}

(Received March 23, 1982)

\begin{abstract}
Lithium $N$-methylanilide, prepared from $N$-methylaniline and $n$-butyllithium, readily absorbed $\mathrm{CO}$ at atmospheric pressure in the presence of cuprous iodide to produce a CO-containing copper complex. Treatment of this complex with organic halides gave the corresponding amides in good yields.
\end{abstract}

Keywords__ carbonylation; carbamoylation; carbon monoxide; cuprous iodide; lithium $N$-methylanilide

Carbonylations of amines with various catalysts have been investigated extensively.,2) Most of these reactions require high temperature and pressure, and the results depend greatly on the reaction conditions and catalysts used. Saegusa et al. have reported ${ }^{3)}$ that lithium bis( $N, N$-diethylcarbamoyl)cuprate, prepared from $\mathrm{CO}$ and lithium bis( $N, N$-diethylamino)cuprate at $1-50 \mathrm{~kg} / \mathrm{cm}^{2}$, is a useful reagent for direct carbamoylation. The corresponding carbamoylcopper complex derived from aniline, however, has been shown to be ineffective for carbamoylation. We have found that lithium $N$-methylanilide, ${ }^{4)}$ prepared in situ from $N$-methylaniline and $n$-butyllithium, smoothly absorbs $\mathrm{CO}$ at atmospheric pressure on addition of $\mathrm{CuI}$ to the reaction system, and subsequent treatment with $\mathrm{CH}_{3} \mathrm{I}$ gives $\mathrm{N}$-methylacetanilide (2) in good yield.

The influence of the molar ratio of $\mathrm{CuI}$ to $N$-methylaniline on the yield of (2) was investigated to optimize the reaction conditions. The results are summarized in Table I. The maximum yield of (2) was obtained when a $0.5 / 1 \mathrm{CuI} / N$-methylaniline molar ratio was used. In the case of a $0.25 / 1 \mathrm{CuI} / N$-methylaniline molar ratio, the yield of (2) decreased, and a signi-

TABLE I. Relationship between CuI/N-Methylaniline Molar Ratio and the Yields of Products in the Carbamoylation of Methyl Iodide ${ }^{a}$

\begin{tabular}{|c|c|c|c|}
\hline \multirow{2}{*}{$\begin{array}{c}\mathrm{CuI} / N \text {-Methylaniline } \\
\text { molar ratio }\end{array}$} & \multirow{2}{*}{ Time $(h)^{b l}$} & \multicolumn{2}{|c|}{ Products, $\%$ yields ${ }^{c)}$} \\
\hline & & 2 & 3 \\
\hline 0.25 & 3.5 & 35 & 65 \\
\hline 0.5 & 3.5 & 71 & 28 \\
\hline 0.5 & 7.0 & 64 & 30 \\
\hline 0.67 & 3.5 & $65(64.6)^{e)}$ & 24.5 \\
\hline $1.0^{d)}$ & 3.0 & $(54)^{e)}$ & \\
\hline 1.0 & 3.5 & 62 & 34 \\
\hline 1.5 & 3.5 & 59 & \\
\hline 2.0 & 3.5 & 56 & 29 \\
\hline
\end{tabular}

a) The mixture obtained by addition of $\mathrm{CuI}(0.25-2.0 \mathrm{eq})$ to lithium $N$-methylanilide in anhydrous ether was allowed to react with $\mathrm{CO}$ at atmospheric pressure and $0^{\circ} \mathrm{C}$, and subsequently with $\mathrm{CH}_{3} \mathrm{I}$ $(2 \mathrm{eq})$ for $12 \mathrm{~h}$ at room temperature.

b) Reaction time with $\mathrm{CO}$.

c) Yields are based on $N$-methylaniline and were determined by gas chromatographic analysis using an internal standard.

d) Lithium $N$-methylanilide was added dropwise to a suspension of $\mathrm{CuI}$ in ether.

e) Isolated yields. 
ficant reduction in the yield was also observed on increasing the molar ratio of CuI to $\mathrm{N}$ methylaniline. Our initial attempts to isolate and identify a white precipitate, produced in the equimolar reaction of lithium $\mathrm{N}$-methylanilide and $\mathrm{CuI}$, were unsuccessful. On the basis of a general preparation of $\mathrm{RCu}$ species and lithium diorganocuprate(I) reagents, ${ }^{5)}$ and the reactivity of these species reported previously, ${ }^{3,6)}$ the most likely pathway for the carbamoylation of $\mathrm{CH}_{3} \mathrm{I}$ would involve lithium bis ( $N$-methyl- $N$-phenylcarbamoyl)cuprate (1) as a reactive $\mathrm{CO}$-containing copper complex, though the available data are not sufficient to allow formulation of a detailed course of the reaction.

TABle II. Reactions of the CO-Containing Copper Complex with Organic Halides at $0.5 / 1 \mathrm{CuI} / N$-Methylaniline Molar Ratio

\begin{tabular}{ccc}
\hline Organic halides $^{a}$ & Time $(\mathrm{h})^{b)}$ & Isolated products $(\%)^{c)}$ \\
\hline Allyl bromide & 1 & $\mathbf{4}(88)$ \\
Acetyl bromide & 1 & $\mathbf{5}(72)$ \\
Benzyl bromide & 12 & $\mathbf{6}(13), 8(10)$ \\
Iodobenzene & 84 & $\mathbf{7}(5), 8(4.5)$ \\
\hline
\end{tabular}

a) Two eq of organic halide with respect to $N$-methylaniline was added. b) Reaction time with organic halides. c) Yields are based on $N$-methylaniline.

The reactions with other organic halides were carried out at $0.5 / 1 \mathrm{CuI} / N$-methylaniline molar ratio, as shown in Table II. Addition of allyl bromide to a white suspension of the COcontaining copper complex produced an immediate yellow coloration including a small amount of black precipitate, and subsequent hydrolysis gave the corresponding allyl amide (4) in $88 \%$ yield. Similarly, $N$-methyl-2-oxo- $N$-phenylpropanamide (5) was obtained in $72 \%$ yield by carbamoylation of acetyl bromide. Carbamoylations of benzyl bromide and iodobenzene were examined and the corresponding amides (6) and (7) were obtained, respectively, but in less satisfactory yields.

\begin{tabular}{|c|c|c|}
\hline$\left[\mathrm{C}_{6} \mathrm{H}_{5} \mathrm{~N}\left(\mathrm{CH}_{3}\right) \mathrm{CO}\right]_{2} \mathrm{CuLi}$ & $\mathrm{C}_{6} \mathrm{H}_{5} \widehat{V}_{\mathrm{R}}^{\mathrm{CH}_{3}}$ & \\
\hline 1 & $\begin{array}{l}2: \mathrm{R}=\mathrm{COCH}_{3} \\
3: \mathrm{R}=\mathrm{CH}_{3} \\
4: \mathrm{R}=\mathrm{COCH}_{2} \mathrm{CH}=\mathrm{CH}_{2} \\
5: \mathrm{R}=\mathrm{COCOCH}_{3} \\
6: \mathrm{R}=\mathrm{COCH}_{2} \mathrm{C}_{6} \mathrm{H}_{5}\end{array}$ & $\begin{aligned} 7 & : \mathrm{R}=\mathrm{COC}_{6} \mathrm{H}_{5} \\
8 & \left.: \mathrm{R}=\mathrm{COCON} \mathrm{CH}_{3}\right) \mathrm{C}_{6} \mathrm{H}_{5} \\
9 & : \mathrm{R}=\mathrm{CONHC} \mathrm{H}_{5} \\
10 & : \mathrm{R}=\mathrm{CO}\left(\mathrm{CH}_{3}\right) \mathrm{C}_{6} \mathrm{H}_{5} \\
11: & \mathrm{R}=\mathrm{COCH}_{2} \mathrm{CH}(\mathrm{OH}) \mathrm{C}_{6} \mathrm{H}_{5}\end{aligned}$ \\
\hline & Chart 1 & \\
\hline
\end{tabular}

$N, N^{\prime}$-Dimethyl- $N, N^{\prime}$-diphenylethanediamide (8), obtained as a by-product in the carbamoylations of benzyl bromide and iodobenzene, appears to be an oxidative dimerization product arising from the organic group in the CO-containing copper complex. Thus, actual oxidation of the CO-containing copper complex by the addition of nitrobenzene as an oxidant gave (8) and $N$-methylcarbanilide (9) in 40 and $25 \%$ yields, respectively. On the other hand, in the reaction of the CO-containing copper complex with $N$-bromosuccinimide (NBS), $N, N^{\prime}$-dimethylcarbanilide $(\mathbf{1 0})$ was obtained in $46 \%$ yield. Furthermore, similar treatment with 1,2epoxyethylbenzene gave the expected 3-hydroxy- $N$-methyl- $N$-phenyl-3-phenylpropanamide (11) in $52 \%$ yield.

\section{Experimental}

Melting points are uncorrected. ${ }^{1} \mathrm{H}-\mathrm{Nuclear}$ magnetic resonance ( ${ }^{1} \mathrm{H}-\mathrm{NMR}$ ) spectra were obtained with a JEOL PS-100 spectrometer in $\mathrm{CDCl}_{3}$ solutions with TMS as an internal reference. Infrared (IR) spectra were recorded with a JASCO IRA-1 spectrophotometer. Mass spectra (MS) were determined on a 
JEOL D-300 or DX-300 mass spectrometer. Analytical gas chromatography (GC) was performed with a Hitachi 063 chromatograph equipped with a flame ionization detector and a stainless steel column $(1 \mathrm{~m} \times 3$ $\mathrm{mm}$ ) packed with $5 \%$ Carb Wax $20 \mathrm{M}$ on $60-80$ mesh chromosorb WAW was used at $150^{\circ} \mathrm{C}$. Column chromatography was carried out on silica gel (70-230 mesh, Merck). All reactions were carried out under dry nitrogen.

Preparation of the Co-containing Copper Complex derived from Lithium $\boldsymbol{N}$-Methylanilide-A solution of $18.7 \mathrm{mmol}$ of $N$-methylaniline in $45 \mathrm{ml}$ of anhydrous ether was placed in a reaction vessel equipped with a balloon. To this stirred solution was added $12 \mathrm{ml}$ of $15 \% n$-butyllithium in hexane at $0^{\circ} \mathrm{C}$. The resulting pale yellow solution was stirred for $1 \mathrm{~h}$ and exposed to carbon monoxide for $0.5 \mathrm{~h}$ at $0^{\circ} \mathrm{C}$ to inactivate excess n-butyllithium. ${ }^{4}$ A given amount (4.68-37.4 mmol) of purified CuI was added slowly to the yellow solution at $0^{\circ} \mathrm{C}$; when the $\mathrm{CuI} / N$-methylaniline molar ratios were 0.5 and 0.25 , the reaction mixture was homogeeous, while it was heterogeneous otherwise. The mixture was allowed to react with carbon monoxide at the same temperature for the time shown in Table I; when using $0.25 / 1$ and $0.5 / 1 \mathrm{CuI} / N$-methylaniline molar ratios, a white precipitate rapidly developed, while in the cases of more than $0.67 / 1$ molar ratio, the reaction of the suspension with $\mathrm{CO}$ was heterogeneous throughout the initial transient homogeneous state.

Carbamoylation of Methyl Iodide- The CO-containing copper complex prepared as described above was treated with $37.4 \mathrm{mmol}$ of $\mathrm{CH}_{3} \mathrm{I}$, and the mixture was stirred for $12 \mathrm{~h}$ at room temperature. After hydrolysis in water, the mixture was filtered and extracted with ether. The combined extracts were dried $\left(\mathrm{Na}_{2} \mathrm{SO}_{4}\right)$ and concentrated. The yields of the products, $N, N$-dimethylaniline $(3)$ and $N$-methylacetanilide (2), were determined by column chromatographic separation or GC analysis using $\beta$-methoxynaphthalene as an internal standard, as shown in Table I. The products (2) and (3) were identified by comparison of GC retention times and IR data with those of authentic samples.

Carbamoylations of Organic Halides_- The CO-containing copper complex prepared in $0.5 / 1 \mathrm{CuI} / \mathrm{N}$ methylaniline molar ratio as described above was treated with $37.4 \mathrm{mmol}$ of organic halide, and the mixture was stirred for the time shown in Table II. The mixture was worked up as described above.

A) With Allyl Bromide: The crude product was purified by chromatography on silica gel with $n$ hexane-ethyl acetate $(3: 1)$ to give $N$-methyl- $N$-phenyl-3-butenamide $(4)$ as a colorless oil $(2.88 \mathrm{~g}, 88 \%)$. IR (Neat) $v_{\max } \mathrm{cm}^{-1}: 1670(\mathrm{C}=\mathrm{O}) .{ }^{1} \mathrm{H}-\mathrm{NMR} \delta: 2.9\left(2 \mathrm{H}, \mathrm{d}, J=7 \mathrm{~Hz},-\mathrm{CH}_{2^{-}}\right), 3.25\left(3 \mathrm{H}, \mathrm{s}, \mathrm{NCH}_{3}\right), 4.9(1 \mathrm{H}, \mathrm{dm}$, $\left.J=17 \mathrm{~Hz},=\mathrm{CH}_{2}\right), 5.05\left(1 \mathrm{H}, \mathrm{dm}, J=9 \mathrm{~Hz},=\mathrm{CH}_{2}\right), 5.9(1 \mathrm{H}, \mathrm{ddt}, J=17,9,7 \mathrm{~Hz},-\mathrm{CH}=), 7.1-7.5(5 \mathrm{H}, \mathrm{m}$, aromatic). MS m/e: $175\left(\mathrm{M}^{+}\right)$. Anal. Calcd for $\mathrm{C}_{11} \mathrm{H}_{13} \mathrm{NO}: \mathrm{C}, 75.40 ; \mathrm{H}, 7.48 ; \mathrm{N}, 7.99$. Found: C, 75.15; $\mathrm{H}, 7.52 ; \mathrm{N}, 8.03$.

B) With Acetyl Bromide: The crude product was purified by chromatography on silica gel with $n$ hexane-ethyl acetate $(3: 1)$ to give (5) as a pale yellow oil $(2.38 \mathrm{~g}, 72 \%)$. IR (Neat) $v_{\max } \mathrm{cm}^{-1}: 1730\left(\mathrm{COCH}_{3}\right)$, $1660\left(\mathrm{NCH}_{3} \mathrm{CO}\right) . \quad{ }^{1} \mathrm{H}-\mathrm{NMR} \delta: 2.2\left(3 \mathrm{H}, \mathrm{s}, \mathrm{COCH}_{3}\right), 3.3\left(3 \mathrm{H}, \mathrm{s}, \mathrm{NCH}_{3}\right), 7.1-7.5(5 \mathrm{H}, \mathrm{m}$, aromatic $)$. MS $m / e:$ $177\left(\mathrm{M}^{+}\right)$. Anal. Calcd for $\mathrm{C}_{10} \mathrm{H}_{11} \mathrm{NO}_{2}: \mathrm{C}, 67.78 ; \mathrm{H}, 6.26 ; \mathrm{N}, 7.91$. Found: $\mathrm{C}, 67.87 ; \mathrm{H}, 6.31 ; \mathrm{N}, 8.06$.

C) With Benzyl Bromide: The crude product was purified by chromatography on silica gel with $n$ hexane-ethyl acetate $(5: 1)$. The first fraction gave $N$-methylphenylacetanilide $(6)$ as a pale yellow oil $(0.533$ $\mathrm{g}, 13 \%)$. IR (Neat) $v_{\max } \mathrm{cm}^{-1}: 1660(\mathrm{C}=\mathrm{O}) . \quad{ }^{1} \mathrm{H}-\mathrm{NMR} \delta: 3.25\left(3 \mathrm{H}, \mathrm{s}, \mathrm{NCH}_{3}\right), 3.45\left(2 \mathrm{H}, \mathrm{s},-\mathrm{CH}_{2}-\right), 6.9-7.5$ $\left(10 \mathrm{H}, \mathrm{m}\right.$, aromatic). MS m/e: $225\left(\mathrm{M}^{+}\right)$. Anal. Calcd for $\mathrm{C}_{15} \mathrm{H}_{15} \mathrm{NO}: \mathrm{C}, 79.97 ; \mathrm{H}, 6.71 ; \mathrm{N}, 6.22$. Found: $\mathrm{C}, 79.39 ; \mathrm{H}, 6.80 ; \mathrm{N}, 6.70$. The second fraction gave colorless crystals $(0.256 \mathrm{~g}, 10 \%)$ of $(8), \mathrm{mp} 107-110^{\circ} \mathrm{C}$. IR (Nujol) $\nu_{\max } \mathrm{cm}^{-1}: 1680$ and $1660(\mathrm{C}=\mathrm{O}) . \quad{ }^{1} \mathrm{H}-\mathrm{NMR} \delta: 3.05\left(6 \mathrm{H}, \mathrm{s}, \mathrm{NCH}_{3} \times 2\right), 6.75-7.4(10 \mathrm{H}$, m, aromatic). MS m/e: $268\left(\mathrm{M}^{+}\right)$. Anal. Calcd for $\mathrm{C}_{16} \mathrm{H}_{16} \mathrm{~N}_{2} \mathrm{O}_{2}: \mathrm{C}, 71.62 ; \mathrm{H}, 6.01 ; \mathrm{N}, 10.44$. Found: $\mathrm{C}, 71.43 ; \mathrm{H}$, $5.94 ; \mathrm{N}, 10.33$.

D) With Iodobenzene: The crude product was purified by chromatography on silica gel eluting with $n$-hexane-ethyl acetate $(2: 1)$. The first fraction gave colorless crystals $(0.187 \mathrm{~g}, 5 \%)$ of $N$-methylbenzanilide (7), $\mathrm{mp} 61-63^{\circ} \mathrm{C}$. This product was identical with an authentic sample. The second fraction gave colorless crystals $(0.113 \mathrm{~g}, 4.5 \%)$ of $(8)$.

Oxidation with Nitrobenzene-A mixture of $18.7 \mathrm{mmol}$ of nitrobenzene and the CO-containing copper complex prepared in $0.5 / \mathrm{l} \mathrm{CuI} / N$-methylaniline molar ratio as described above was stirred for $12 \mathrm{~h}$ at room temperature. After the mixture had been worked up as described above, the crude product was purified by chromatography on silica gel with $n$-hexane-ethyl acetate $(2: 1)$. The first fraction gave colorless crystals $(1.0 \mathrm{~g}, 25 \%)$ of $(9), \mathrm{mp} 102-103^{\circ} \mathrm{C}$. IR (Nujol) $v_{\max } \mathrm{cm}^{-1}: 3240(\mathrm{NH}), 1660(\mathrm{C}=\mathrm{O}) .{ }^{1} \mathrm{H}-\mathrm{NMR} \delta: 3.35(3 \mathrm{H}, \mathrm{s}$, $\left.\mathrm{NCH}_{3}\right), 6.25\left(1 \mathrm{H}\right.$, br s, NH) $7.0-7.5\left(10 \mathrm{H}, \mathrm{m}\right.$, aromatic). MS m/e: $226\left(\mathrm{M}^{+}\right)$. Anal. Calcd for $\mathrm{C}_{14} \mathrm{H}_{14} \mathrm{~N}_{2} \mathrm{O}$ : $\mathrm{C}, 74.31 ; \mathrm{H}, 6.24 ; \mathrm{N}, 12.38$. Found: $\mathrm{C}, 74.07 ; \mathrm{H}, 6.39 ; \mathrm{N}, 11.87$. The second fraction gave colorless crystals $(1.0 \mathrm{~g}, 40 \%)$ of $(8)$.

Reaction with $\boldsymbol{N}$-Bromosuccinimide (NBS)__ A mixture of $18.7 \mathrm{mmol}$ of NBS and the CO-containing copper complex in $0.5 / 1 \mathrm{CuI} / N$-methylaniline molar ratio as described above was stirred for $12 \mathrm{~h}$ at room temperature. After the mixture had been worked up as described above, the crude product was purified by chromatography on silica gel with $n$-hexane-ethyl acetate $(3: 1)$. The first fraction gave colorless crystals $(1.022 \mathrm{~g}, 46 \%)$ of $(10), \mathrm{mp} 116-118^{\circ} \mathrm{C} . \quad$ IR (Nujol) $v_{\max } \mathrm{cm}^{-1}: 1660(\mathrm{C}=\mathrm{O}) . \quad{ }^{1} \mathrm{H}-\mathrm{NMR} \delta: 3.15\left(6 \mathrm{H}, \mathrm{s}, \mathrm{NCH}_{3} \times\right.$ 2), 6.7-7.1 (10H, m, aromatic). High resolution MS $m / e$ : Calcd for $\mathrm{C}_{15} \mathrm{H}_{16} \mathrm{~N}_{2} \mathrm{O}\left(\mathrm{M}^{+}\right)$240.12623. Observed: 240.12560. The second fraction gave colorless crystals $(0.8 \mathrm{~g}, 32 \%)$ of $(8)$.

Reaction with 1,2-Epoxyethylbenzene-The CO-containing copper complex prepared in $0.5 / 1 \mathrm{CuI} / N$ - 
methylaniline molar ratio as described above was cooled to $-78^{\circ} \mathrm{C}$ and $4.68 \mathrm{mmol}$ of 1 ,2-epoxyethylbenzene was added with stirring. The stirring was continued overnight and the temperature was allowed to rise to room temperature. After the mixture had been worked up as described above, the crude product was purified by chromatography on silica gel with $n$-hexane-ethyl acetate $(2: 1)$ to give colorless crystals $(0.62 \mathrm{~g}, 52 \%$ based on 1,2-epoxyethylbenzene) of $(11), \mathrm{mp} 108-109^{\circ} \mathrm{C}$. IR (Nujol) $v_{\max } \mathrm{cm}^{-1}: 3360(\mathrm{OH}), 1630(\mathrm{C}=\mathrm{O})$. ${ }^{1} \mathrm{H}-\mathrm{NMR} \delta: 2.45\left(2 \mathrm{H}, \mathrm{d}, J=7 \mathrm{~Hz}, \mathrm{COCH}_{2}-\right), 3.25\left(3 \mathrm{H}, \mathrm{s}, \mathrm{NCH}_{3}\right), 4.75(1 \mathrm{H}, \mathrm{d}, J=4 \mathrm{~Hz}, \mathrm{OH}), 5.05(1 \mathrm{H}, \mathrm{td}$, $\left.J=7,4 \mathrm{~Hz},-\mathrm{C}^{\mathrm{C}} \mathrm{H}-\right), 7.0-7.4\left(10 \mathrm{H}, \mathrm{m}\right.$, aromatic). MS m/e: $255\left(\mathrm{M}^{+}\right)$. Anal. Calcd for $\mathrm{C}_{16} \mathrm{H}_{17} \mathrm{NO}_{2}: \mathrm{C}_{3}, 75.27$; $\mathrm{H}, 6.71 ; \mathrm{N}, 5.49$. Found: $\mathrm{C}, 75.21 ; \mathrm{H}, 6.70 ; \mathrm{N}, 5.41$.

Acknowledgement The authors thank the Ministry of Health and Welfare, Japan, for financial support.

\section{References and Notes}

1) For reviews, see: C.W. Bird, Chem. Rev., 62, 283 (1962); J. Falbe, "New Syntheses with Carbon Monoxide," Springer-Verlag, Berlin, Heidelberg, New York, 1980, p. 291.

2) V. Rautenstrauch and M. Joyeux, Angew. Chem. Int. Ed. Engl., 18, 83 (1979); V. Rautenstrauch and M. Joyeux, ibid., 18, 85 (1979); V. Rautenstrauch and F. Delay, ibid., 19, 726 (1980).

3) T. Saegusa, T. Tsuda and M. Miwa, J. Org. Chem., 44, 3734 (1979).

4) Lithium $N$-methylanilide did not react with $\mathrm{CO}$ at atmospheric pressure; see also ref. 2.

5) A.E. Jukes, "Advances in Organometallic Chemistry," Vol. 12, ed., F.G.A. Stone and R. West, Academic Press, Inc., New York, 1974, pp. 215-322.

6) T. Saegusa, T. Tsuda, K. Nishijima and K. Isayama, Tetrahedron Lett., 1968, 3379. 